\title{
Dramaturgias do silêncio na tragédia grega
}

José Pedro Serra

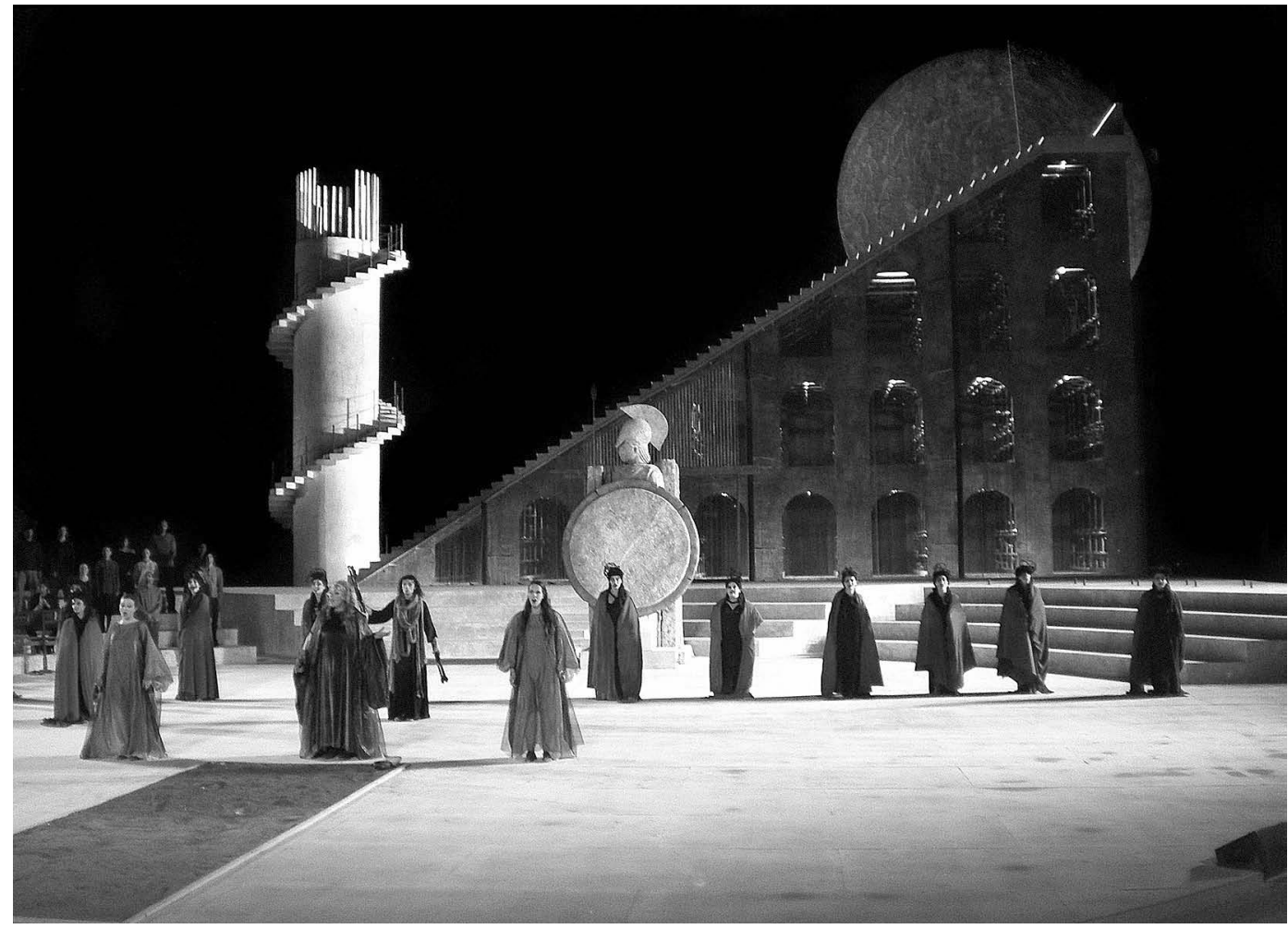

A dramaturgia contemporânea outorgou ao silêncio um relevo nunca antes concedido, não o entendendo apenas como potencial recurso da encenação, de algum modo deixado ao arbítrio do encenador ou do actor, mas transformando-o em objecto e em tema do drama. As modernas didascálias que ao silêncio se referem provam a atenção e a importância que Ihe são atribuídas. Ionesco, Pinter, Strauss, Beckett colocam dramaticamente a questão do significado substancial do silêncio, atirado contra o espectador como algo muito mais profundo e decisivo do que uma estratégia dramática. 0 anúncio da "morte de Deus", o desamparo existencial que dessa suprema morte decorre, o sentimento de abandono, de incomunicabilidade e de solidão extrema, agravado por se dar e crescer no meio das multidões, deram à linguagem, ao que nela é falhanço, manipulação e incompletude, uma ressonância e um amargo sabor até agora desconhecidos. A emergência da importância dramática do silêncio não é separável da agonia existencial e da ameaça do vazio que atravessa o quadro cultural do século XX.
Os tragediógrafos gregos conheceram e deram a ver o que a seus olhos aparecia como os grandes horrores da existência: homens, nobres e heróicos, esmagados às mãos do destino; deuses que brincam com a nossa mortal condição; terriveis e enganosos equivocos que fazem colher morte e infelicidade em campos semeados de justas intenções; parricídio e incesto encontrados no fundo inconsciente de um acto libertador. 0 rol das desgraças e das visões inquietantes é longo. Ainda assim, jamais se duvida da verdade e da autenticidade do sofrimento dito e exposto. A dor, o medo, a vulnerabilidade do coração humano, os limites da sua compreensão ali estão confiadamente ditos e percebidos, numa formulação verbal que palpita de verdade. A visão faz tremer, mas não desconfiar da palavra; cria um inquietante trilho de pensamento, mas não um asfixiante deserto mudo e vazio. 0 absurdo não integra o trágico grego, nem na tragédia grega as palavras definham ao sopro de uma gélida brisa que perdeu ou esqueceu o sentido do mundo e da vida. 0 horror ali está, dito e visto, mas a possibilidade de 0 envolver pela palavra e de o identificar marca o início da
José Pedro Serra

é Professor do Departamento de Estudos Clássicos d Faculdade de Letras da Universidade de Lisboa e investigador do Centro de Estudos Clássicos da mesma Faculdade. 


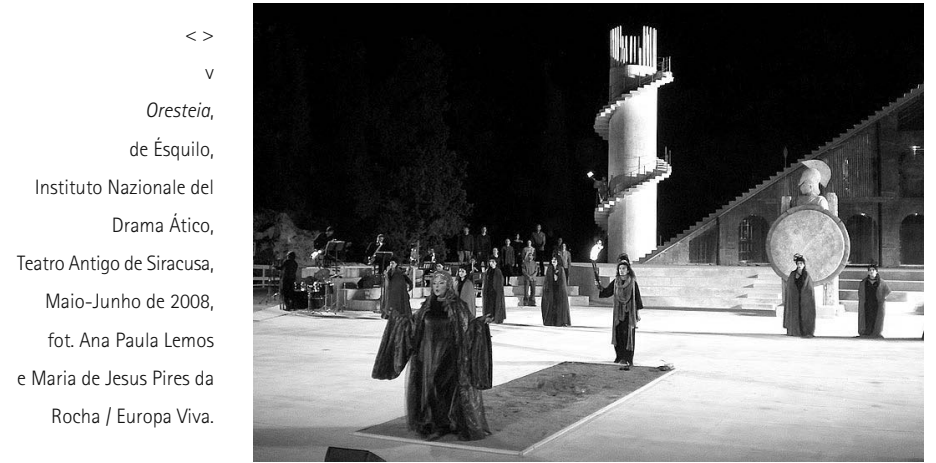

batalha para o defrontar e vencer. Não obstante esta confiança na palavra e no que dela pode resultar, os tragediógrafos gregos não foram indiferentes às potencialidades dramáticas do silêncio e aos efeitos emocionais da sua presença. Tais factos eram conhecidos não apenas dos autores dos textos, mas também dos espectadores. Em As rãs, Aristófanes imagina um diálogo entre Dioniso, Ésquilo e Eurípides, estes disputando a primazia na fama e na glória da criação de tragédias:

\section{EUR. - (...) Logo de entrada, ele fazia sentar uma figura} qualquer velada, um Aquiles ou uma Niobe, ocultando-Ihe o rosto, figuras de tragédia que não tugiam nem mugiam... (...) E o coro apoiava umas nas outras quatro séries de cantos, de seguida, continuamente, enquanto as personagens estavam caladas.

DIO. - (...) Mas porque é que ele procedia assim, esse sujeito? EUR. - Por gabarolice, para que o espectador ficasse sentado, na expectativa de ver quando Niobe diria qualquer coisa. E o drama prosseguia. (...)

E depois, quando já tinha feito estes disparates e a peça já estava a meio, pronunciava doze palavras do tamanho de bois (...). (Aristófanes 1996: vv. 905ss)

Perdidas as tragédias onde estas cenas eram representadas, uma nuvem de alguma obscuridade envolve as referências de Aristófanes. Descontando o exagero da ironia e da troça próprias à comédia, é, porém, indiscutive o peso e o significado dramático dos silêncios de Aquiles e de Níobe e da sua ressonância junto do público ateniense. Se assim não fosse, Aristófanes não os usaria na sua mordaz crítica. 0 renitente e persistente silêncio de Níobe junto à sepultura dos seus filhos, esse silêncio que tarda a abrirse em palavra, tem uma força trágica que se impõe. Igualmente relevante e teatral é o silêncio de Aquiles, cabeça coberta tal como Niobe, em mudez chorando a sua sorte de herói publicamente insultado por Agamémnon. Neste contexto, mais do que as palavras, o resistente silêncio de Níobe ou de Aquiles marca uma ruptura e uma incompatibilidade com o mundo, uma impossibilidade de se tornar cúmplice com a vida quando dela foram ceifados os mais amados. A dor, de tão intensa, trespassa a palavra e coroa-se em silêncio. Não há absurdo, há dor extrema, e de tal extremidade, silêncio.

Há diversos tipos de silêncio que correspondem a diversas situações dramáticas; entre outros, há o carregado silêncio de Prometeu no início do Prometeu agrilhoado, surdo desafio lançado aos altos poderes; ou o silêncio que Orestes, nas Euménides, opõe às Erínias; ou o silêncio com que Antígona, desobedecendo ao édito e obedecendo às
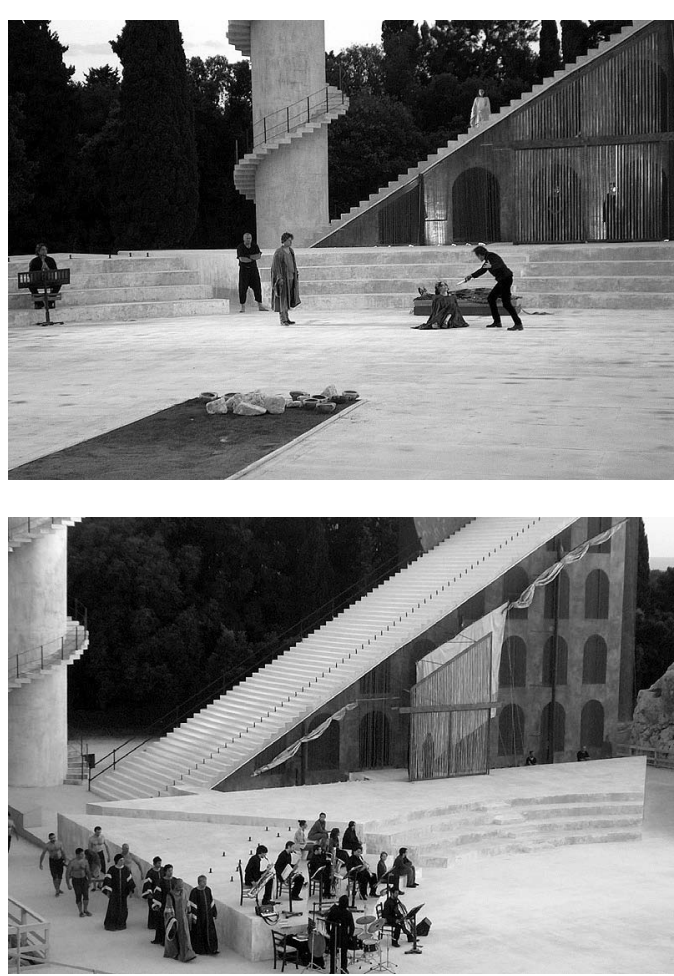

leis eternas e não escritas, resiste ao poder de Creonte; ou o cúmplice silêncio de Fedra no Hipólito de Euripides. Refiro apenas duas situações extraídas da Oresteia.

Regressado de Tróia, glorioso vencedor da guerra, Agamémnon traz consigo Cassandra, a filha do vencido rei Príamo. A princesa é o sinal evidente da vitória, nobre rosto dominado às mãos do rei poderoso entre os poderosos. Por ter sido avessa aos amores de Apolo, Cassandra arrasta consigo a vingativa maldição do deus: traído no desejo amoroso e enganado na palavra, Apolo concede-lhe o dom da profecia, mas retira-Ihe o crédito, esterilizando e amargando a dávida - Cassandra profetizará a verdade, as suas palavras anteciparão o que o tempo trará, mas ninguém acreditará nela. A voz próxima tornou-se estranha e distante, o prudente e avisado gesto tornou-se inconsequente e petrificou-se numa impotente passividade.

Em Argos, Clitemnestra, simulando os cuidados de uma boa esposa, prepara para Agamémnon uma morte cruel: nas suas maquinações, projecta assassinar o rei enquanto este se banha. Nú, enredado, e por isso domado, às mãos de uma mulher e não de um bravo guerreiro, assim, por ironia, cairá o vencedor dos troianos. 0 espectador não o sabe. Não ignora a perfídia da rainha ilustrada na desordem da cidade, mas o seu olhar não alcança a negritude que se aproxima.

Cassandra acompanha Agamémnon desde que este entra em cena (v. 784) e mantém-se silenciosa durante um logo tempo (v. 1073). Sob os seus olhos oraculares desenrola-se o logro, a enganosa sedução; com palavras hábeis, mascaradas de belas intenções, Clitemnestra leva o filho de Atreu a pisar o tapete de púrpura (honra reservada aos deuses) e a entrar no palácio. A presença muda, grave e austera da princesa troiana não pode deixar de impressionar o espectador e de prender, inquietantemente, a sua atenção. É certo que ela é uma cativa, um prémio de guerra, mas o seu porte é real. Hirta, imóvel, orgulhosa na sua infortunada altivez, austera e gravemente 


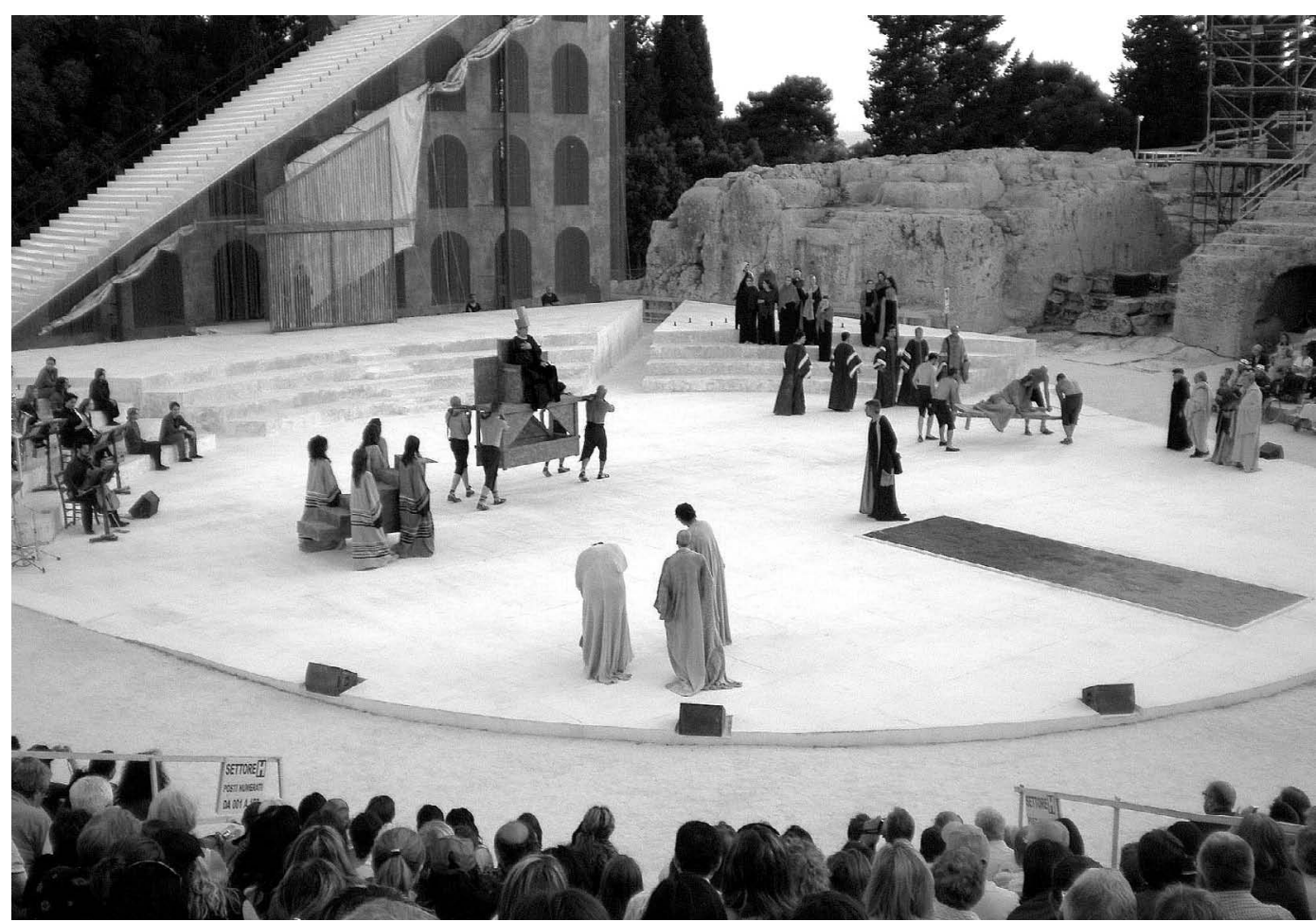

Oresteia,

de Ésquilo,

Instituto Nazionale del

Drama Ático

Teatro Antigo de Siracusa,

Maio-Junho de 2008,

fot. Ana Paula Lemos

e Maria de Jesus Pires da

Rocha / Europa Viva.

desdenhosa na certeza da perdição irremissivel - assim a imagino eu, seguindo a lógica do "drama".

0 significado desse silêncio, porém, revela-se quando se quebra, quando explode em palavras proféticas, iniciadas por um lamento que repetidamente profere: "Ai, Oh Apolo, Apolo!" Poderoso mas inconsciente, forte na força, mas fraco na previdência, Agamémnon, inchado de vaidade, prepara-se para entrar no palácio onde encontrará uma morte vergonhosa. A sua morte arrastará com ela a morte de Cassandra. Esta, fraca na força, mas forte no arguto olhar com que olha o futuro, sabe o que irremediavelmente os espera. A voz da princesa, que por excesso de lucidez é incompreensivel para o coro, ergue-se amarga porque o deus transformou o saber em coisa cruel. Cassandra não representa apenas o imenso risco do desejo e da aventura do conhecer, estrada gloriosa que penosa e incompletamente há muito vamos percorrendo, representa também a tragédia da esterilização do saber, limitado a uma petrificada visão privada do gesto. Nela, a graça do conhecimento tornou-se em maldição. Nem as humanas ilusões, que o passar do tempo vai vestindo, a protegem. 0 olhar de Cassandra atravessa o tempo e nessa visão profunda encontra sempre o triunfo da morte.

Em Coéforas, encontramos um outro exemplo de um prolongado silêncio. Em apagado e desprezado exílio depois da morte de Agamémnon, tal como ultrajada e desprezada é Electra, Orestes regressa a casa para vingar o assassínio de seu pai, terrível tarefa para a qual encontra o entusiástico apoio da vingativa irmã. Pílades, o leal amigo, acompanha o vingador no regresso a Argos e ainda na ida ao palácio de Clitemnestra, onde o matricídio terá lugar. A sua presença, porém, é sempre silenciosa. Em silêncio partilha o encontro entre Electra e Orestes; em silêncio assiste ao pacto entre os dois irmãos e ao reforço da intenção de vingar o pai; em silêncio torna-se cúmplice no disfarce que os cobre, a ele e a Orestes; em silêncio assiste ao dramático encontro entre Clitemnestra e o filho.
A persistente presença de Pílades não pode deixar de inquietar o espectador e de atrair sobre ele alguma atenção. Apenas por uma vez, numa breve fala e talvez no momento mais crítico de toda a tragédia, quando a patética súplica da mãe faz hesitar o braço matricida de Orestes, a voz de Pílades se faz ouvir.

\section{CL. - Espera, meu filho, respeita, meu menino, este seio,}

contra o qual muitas vezes a dormir com os lábios mamaste o leite que bem te nutriu.

OR. - Pílades, que hei-de fazer? Será legítimo matar uma mãe?

PÍL. - 0 que será então, no futuro, dos oráculos de Lóxias proferidos pela Pítia, e da confiança dos juramentos? Antes ter todos os homens como inimigos do que os deuses.

(Ésquilo 1998: vv. 896-902)

A sua intervenção, iluminada pelo longo silêncio que a antecede, é decisiva no decorrer da acção dramática e é facilmente perceptível. Paralisado no soluço emocional que o tolhe, Orestes encontra nas palavras de Pilades a orientação e o sentido do seu gesto que por momentos Ihe escapa. Por Pilades, Orestes retoma o caminho que é o seu e, finalmente, o matricídio consumar-se-á. Como alter ego, como voz da consciência, do destino ou do daimon, o silêncio e a voz de Pilades abrem-se a múltiplas leituras.

No fundo, também em silêncio se vai desenhando o gesto.

\section{Referências bibliográficas}

ARISTÓFANES (1996), As rãs, trad. Américo da Costa Ramalho, Lisboa, Edições 70.

ÉSOUILO (1998), Coéforas in Oresteia, trad. Manuel de Oliveira Pulquério, Lisboa, Edições 70 